\title{
Ligand-induced redistribution of membrane macromolecules: some possible implications for cancer
}

\author{
MARTIN C. RAFF AND STEFANELLO de PETRIS \\ From the Medical Research Council Neuroimmunology Project, Zoology Department, University College, \\ London
}

Perhaps the most important recent discovery concerning the structure of cell membranes is that they are essentially fluid, with lipid and protein molecules capable of moving relative to one another in the plane of the membrane (Frye and Edidin, 1970; Singer and Nicolson, 1972; de Petris and Raff, 1972). At present a generally accepted model of a cell membrane is that of a fluid lipid bilayer, into or through which globular proteins variably penetrate and 'float', with their non-polar regions interacting with the hydrophobic interior of the bilayer and their polar regions exposed to the internal and/or external aqueous environment (Singer and Nicolson, 1972).

The evidence for this 'fluid mosaic' model of the membrane has come from a variety of sources. We are concerned here only with one part of the evidence. It involves the observations that when multivalent or divalent antibodies or ligands interact with macromolecules on the surface of living cells, the macromolecules undergo a dramatic redistribution in the plane of the membrane (Taylor, Duffus, Raff, and de Petris, 1971 ; Loor, Forni, and Pernis, 1972). In the context of this symposium it seems reasonable to ask if this phenomenon, which has provided insight into the fluid structure of normal cell membranes, has any implications for cancer. In particular, we will consider two questions: (1) Is the increased agglutinability of cancer cells (compared to normal cells) by lectins in any way related to the distribution or redistribution of lectin receptors on the surface of these cells? (2) Does ligand-induced redistribution of membrane antigens or receptors play any role in tumour immunity? Before dealing with these specific questions we will briefly review the phenomena of ligand-induced redistribution of membrane macromolecules.

Ligand-induced Patching, Capping, and Pinocytosis of Membrane Macromolecules

One approach to studying cell membranes is to use antibody directed against cell surface antigens. For example, labelled anti-immunoglobulin antibody can be used to detect antigen-specific immunoglobulin (Ig) receptors on the surface of lymphocytes by immunofluorescence or immunoferritin electron microscopy. When fluorescein or ferritin-labelled monovalent Fab, ie, papain-digested, anti-Ig is used to label living lymphocytes, labelling is diffuse and disordered, presumably representing the normal distribution of $\mathrm{Ig}$ in the unperturbed membrane (Taylor et al, 1971; Loor et al, 1972; de Petris and Raff, 1973). On the other hand, when divalent antiIg is used, two different labelling patterns are seen depending on the conditions of labelling, both of which have been shown to represent induced redistribution of the Ig in the membrane (Taylor et al, 1971 ; Loor et al, 1972; de Petris and Raff, 1972). When lymphocytes are labelled with divalent anti-Ig at $0-4{ }^{\circ} \mathrm{C}$ and/or in the presence of metabolic inhibitors, such as sodium azide, labelling occurs in large patches all around the cell. This 'patch formation' appears to be a passive process and is probably due to cross-linking of the mobile membrane Ig molecules by anti-Ig and the formation of twodimensional lattices or microagglutinates of Ig-antiIg complexes. Although patching occurs in the presence of metabolic inhibitors and at temperatures as low as $0^{\circ} \mathrm{C}$ it can be inhibited by fixing the cells with $4 \%$ formaldehyde for three hours (unpublished observations). If cells labelled with divalent anti-Ig are warmed to $20-37^{\circ} \mathrm{C}$ in the absence of metabolic inhibitors, within minutes the labelled patches segregate from the unlabelled parts of the membrane and gather over the Golgi pole of the lymphocytes, forming 'caps', following which they are pinocytosed. The pinocytosis leads to a progressive loss of the Ig-anti-Ig complexes, and in many cells all of the surface $\mathrm{Ig}$ disappears by one to two hours. If such cells are washed and put into culture surface Ig returns in six to 20 hours (Loor et al, 1972), consistent with the normal turnover time for membrane Ig on lymphocytes (Vivetta and Uhr, 1972) and 
for membrane macromolecules in general (Warren and Glick, 1968). Cap formation and pinocytosis are active phenomena, which are markedly inhibited in the cold and by metabolic inhibitors, and probably involve contractile microfilament activity, since they are partially inhibited by Cytochalasin B (Taylor $e t$ al, 1971).

Ligand-induced redistribution of membrane macromolecules is not confined to Ig on lymphocytes. Patching and to a lesser extent capping have been observed for a large number of different surface components on various types of nucleated cells (Raff and de Petris, 1973; Edidin and Weiss, 1972; Sundqvist, 1972). Two generalizations which seem to be valid for lymphocytes will probably hold for a large number of macromolecules on most nucleated cells: (1) Membrane macromolecules are diffusely and randomly distributed, and observed distributions different from this are usually artifactual, induced by the multivalent ligands used to demonstrate them. (2) Membrane determinants which are on separate molecules redistribute, ie, patch and cap, independently of each other (Taylor et al, 1971; Bernoco, Cullen, Scudeller, Trinchieri, and Ceppellini, 1972; Neauport-Sautes, Lilly, Silvestre, and Kourilsky, 1973).

Differential Agglutinability of Transformed versus Normal Cells by Lectins: Is Lectin Receptor Distribution and/or Redistribution the Difference?

Besides causing tumours in vivo, cells transformed by a variety of carcinogenic agents have been shown to differ from normal cells in their behaviour in vitro. Thus, normal cells stop growing on contact with each other (contact inhibition of growth) (Stoker, 1964), and are in general poorly agglutinated by various plant lectins such as Concanavalin $\mathbf{A}$ (Con A) (Burger and Goldberg, 1967; Inbar and Sachs, 1969), whereas transformed cells fail to show contact inhibition (Vogt and Dulbecco, 1960; Borek and Sachs, 1966) and are usually readily agglutinated by lectins (Burger and Goldberg, 1967; Inbar and Sachs, 1969). Normal cells treated with low concentrations of proteolytic enzymes (Burger, 1969; Inbar and Sachs, 1969), urea (Weston and Hendricks, 1972), or protein synthesis inhibitors (Baker and Humphreys, 1972) behave in vitro like transformed cells, both in respect of contact inhibition and in their agglutinability by lectins. This striking (but not invariable) correlation between lectin agglutinability and growth control in vitro suggests that lectin agglutinability may reflect an important rather than a trivial difference between normal and tumour cells, but what difference and how it is related to growth control in vivo is unclear.
Since all cells have surface glycoproteins which bind lectins, ie, lectin receptors, it is reasonable to assume that lectins agglutinate cells by crosslinking and bridging them, a notion which is consistent with the finding, which we have confirmed, that on lectin-agglutinated cells the lectin is always found at the points of cell contact (Nicolson, 1972) Why then are normal fibroblast lines, eg, 3T3 cells, not agglutinated by concentrations of lectin which markedly agglutinate transformed or trypsinized fibroblasts? The simplest explanation that the density of exposed lectin sites is much less on normal than on transformed or trypsinized cells seems not to be the case, since both agglutinable and nonagglutinable cells have been shown under some circumstances at least to bind similar numbers of radiolabelled lectin molecules per unit area of cell (Sela, Lis, Sharon, and Sachs, 1971; Arndt-Jovin and Berg, 1971; Inbar, Ben-Bassat, and Sachs, 1971). Recently, Nicolson has reported that the distribution of Con A-ferritin on the surface of $\mathrm{SV}_{40}$-transformed (Nicholson, 1971) and on trypsinized (Nicolson, 1972) 3T3 cells was patchy, whereas on normal 3T3 cells it was diffuse, suggesting that the clustered lectin receptors on agglutinable cells may provide areas where the crosslinking between cells by lectin can occur with higher avidity. In view of the evidence for ligand-induced redistribution of membrane macromolecules discussed above, it seemed more likely to us that the clustering of Con A binding sites seen by Nicolson was induced by the binding of the multivalent Con A-ferritin, and that the difference between the two types of cells was in the 'redistributability' of the membrane glycoproteins rather than in their original distribution in the unperturbed membrane. Although we (in collaboration with L. Mallucci) have recently obtained evidence to support the first part of our interpretation of Nicolson's experiments, as yet we have not been able to find a difference in the redistribution of Con $A$ receptor sites induced by the binding of Con A-ferritin to agglutinable and non-agglutinable cells.

We have studied the ultrastructural distribution of Con A-ferritin on 3T3 cells, which are not agglutinated by Con $\mathrm{A}$, and on polyoma-transformed and on trypsinized $(0.0001 \%$ for three minutes $) 3 T 3$ cells, which are readily agglutinated by Con $\mathrm{A}$, both in unfixed and prefixed (3\% gluteraldehyde for two hours at $20^{\circ} \mathrm{C}$ ) cell suspensions. In all cell types, Con A-ferritin was distributed in a patchy manner in unfixed cells and in a dispersed, random manner in prefixed cells. This strongly suggests that the clustering of Con A sites seen by Nicolson was induced by the binding of Con A. However, we could not find any obvious difference in the extent 
of clustering at $0-4^{\circ} \mathrm{C}$ or at $20^{\circ} \mathrm{C}$ between the agglutinable and non-agglutinable cells. Although it is not clear why we have not been able to confirm Nicolson's observations, the notion that membrane glycoproteins are aggregated in transformed and trypsinized fibroblasts seems not to be the case. In addition, since the density and distribution of Con A receptor sites was not noticeably different on the three types of cells we studied, these factors alone probably cannot account for the differences in Con A agglutinability. Perhaps differences in surface charge or in exposure of free valencies of bound lectin molecules will turn out to be the important factor(s) determining agglutinability.

\section{Significance of Ligand-induced Membrane Changes in Tumour Immunity}

Most cancer cells express new tumour-specific antigens on their surface and the host usually makes immunological responses against them. Despite this, tumours frequently continue to grow and kill the animal. There are a number of possible explanations for this paradox including the relatively weak immunogenicity of some tumour-specific antigens, and the production of circulating 'blocking' or 'enhancing' factors in the form of antibody, antigen, or antibody-antigen complexes which specifically interfere with the host's tumour-destroying immune responses and thus enhance tumour growth. Clearly the future of immunotherapy for cancer depends on resolving this problem.

There are various ways by which blocking factors might operate. Most simply, antibody, antigen, or antibody-antigen complexes could competitively inhibit the interaction between tumour-specific antigens and the receptors on immunocompetent lymphocytes. However, there are reasons for thinking that blocking factors sometimes act in more complex ways, and it is possible that what has been learned about ligand-induced changes in membrane macromolecule distribution can provide clues to some of these mechanisms. Blocking factors could operate either at the level of the tumour cell or at the level of immunocompetent lymphocytes, and if antibody is involved, either alone or complexed with antigen, these effects have been referred to as peripheral or central enhancement respectively.

One of the best studied examples of peripheral enhancing-like effects of antibody on tumours is the phenomenon of antigenic modulation, described by Boyse, Old, and Luell (1963) for thymus-leukaemia antigens on mouse leukaemia cells. They found that mice making high titres of antithymus-leukaemia antibody were not protected from the lethal effects of thymus-leukaemia ${ }^{+}$leukaemias and showed that this was related to the loss of thymus-leukaemia antigen from the surface of the leukaemia cells. They called this specific loss of surface antigen induced by antibody, antigenic modulation, and were able to demonstrate the same effect in vitro (Old, Stockert, Boyse, and Kim, 1968). Recently, the phenomenon has been described for Ig on lymphocytes and myeloma cells (Takahashi, 1971; Knopf, Destree, and Hyman, 1973) and for H-2 (Takahashi, 1971), and H-LA (Bernoco et al, 1972) on lymphocytes. Although the original studies on thymus-leukaemia modulation had demonstrated that the process was energy dependent, the mechanism remained a mystery until recently. As discussed above, the modulation of $\mathrm{Ig}$ by labelled anti-Ig antibody has been shown to involve pinocytosis of the labelled membrane, and it seems likely that this is the case in most instances of antigenic modulation, although it is possible that active shedding of antibodymembrane-antigen complexes may also occur. There is recent evidence that under some circumstances, when antibody redistributes antigen on the cell membrane, sensitivity of the cell to complementmediated lysis may be lost before the disappearance of the antibody-antigen complexes from the cell surface (Bernoco et al, 1972; our unpublished observations). Thus, antibody-induced 'desensitization' (Knopf et al, 1973) may result either from the loss of antigen, ie, antigenic modulation, or from redistribution of the antibody-antigen complex in the membrane, and in principle soluble antibody or antibody-antigen complexes could protect tumour cells from the cytotoxic effects of antibody and complement, or perhaps from the aggression of cytotoxic cells, by either process. Although it is not clear how important such mechanisms generally are in tumour-bearing animals, the fact that thymusleukaemia ${ }^{+}$leukaemia cells have been shown to protect themselves from the immune response of the host by antigenic modulation (Boyse et al, 1963) suggests that they merit further study.

It is also possible that soluble tumour antigens or antigen-antibody complexes can operate as blocking factors at the level of lymphocytes through a mechanism of immunological tolerance. It is still unknown whether a tolerant lymphocyte is dead or paralysed, and how a lymphocyte decides whether to 'turn on', ie, respond immunologically, or 'turn off', ie, become tolerant, when antigen combines with receptors on its surface. Recently it has been shown that antigen can redistribute receptors on both B (Taylor et al, 1971; Loor et al, 1972; Dunham, Unanue, and Benacerraf, 1972) and T lymphocytes (Ashman and Raff, 1973), raising the possibility that receptor redistribution may be important in the immunity-tolerance decision. The possible impor- 
tance of antibody-antigen complexes as 'blocking factors' (Sjögren, Hellström, Bansal, and Hellström, 1971) and the ratio of antibody to antigen in such complexes (Baldwin, Price, and Robbins, 1972) could reflect the importance of ligand valency in their ability to redistribute membrane macromolecules.

\section{Summary}

The recent observations that membrane macromolecules are mobile in the plane of cell membranes and can undergo dramatic redistribution when they interact with multivalent ligands have led us to consider whether these phenomena could contribute anything to the understanding of cancer. In studies involving the agglutination of normal and transformed cells by Concanavalin A we have failed to find a correlation between the distribution or redistribution of Con A receptor sites and agglutinability. In the realm of tumour immunology we have suggested that soluble tumour-specific antigens, antibodies, or antibody-antigen complexes may operate as blocking or enhancing factors by redistributing antigens on tumour cells or receptors on lymphocytes.

References

Arndt-Jovin, D. J., and Berg, P. (1971). Quantitative binding of ${ }^{125} \mathrm{I}-$ Concanavalin A to normal and transformed cells. J. Virol., 8, 716-721.

Ashman, R., and Raff, M. C. (1973). Direct demonstration of Thetapositive antigen-binding cells with antigen-induced movement of thymus-dependent cell receptors. J. exp. Med., 137, 69-84.

Baker, J. B., and Humphreys, T. (1972). Turnover of molecules which maintain the normal surfaces of contact-inhibited cells. Science, 175, 905-906.

Baldwin, R. W., Price, M. R., and Robbins, R. A. (1972). Blocking of lymphocyte-mediated cytotoxicity for rat hepatoma cells by tumour-specific antigen-antibody complexes. Nature [new Biol.], 238, $185-187$.

Bernoco, D., Cullen, S., Scudeller, G., Trinchieri, G., and Ceppellini, R. (1972). HL-A molecules at the cell surface. Histocompatibility Testing. Munksgaard, Copenhagen. (In press).

Borek, C., and Sachs, L. (1966). The difference in contact inhibition of cell replication between normal cells and cells transformed by different carcinogens. Proc. nat. Acad. Sci. (Wash.), 56, 1705-1711.

Boyse, E. A., Old, L. J., and Luell, S. (1963). Antigenic properties of experimental leukemias. II. Immunological studies in vivo with C57BL/6 radiation-induced leukemias. J. nat. Cancer Inst., 31, 987-995.

Burger, M. M. (1969). A difference in the architecture of the surface membrane of normal and virally transformed cells. Proc. nat. Acad. Sci. (Wash.), 62, 994-1001.

Burger, M. M., and Goldberg, A. R. (1967). Identification of a tumorspecific determinant on neoplastic cell surfaces. Proc. nat. Acad. Sci. (Wash.), 57, 359-366.

de Petris, S., and Raff, M. C. (1972). Distribution of immunoglobulin on the surface of mouse lymphoid cells as determined by immunoferritin electron microscopy. Antibody-induced, temperature-dependent redistribution and its implications for membrane structure. Europ. J. Immunol., 2, 523-534. de Petris, S., and Raff, M. C. (1973). Normal distribution, patching and capping of lymphocyte surface immunoglobulin studied by electron microscopy. Nature [New Biol.], 241, 257-269.

Dunham, E. K., Unanue, E. R., and Benacerraf, B. (1972). Antigen binding and capping by lymphocytes of genetic non-responder mice. J. exp. Med., 136, 403-408.

Edidin, M., and Weiss, A. (1972). Antigen cap formation in cultured fibroblasts: a reflection of membrane fluidity and of cell motility. Proc. nat. Acad. Sci. (Wash.), 69, 2456-2459.

Frye, L. D., and Edidin, M. (1970). The rapid intermixing of cell surface antigens after formation of mouse-human heterokaryons. J. Cell Sci., 7, 319-335.

Inbar, M., Ben-Bassat, H., and Sachs, L. (1971). A specific metabolic activity on the surface membrane in malignant cell-transformation. Proc. nat. Acad. Sci. (Wash.), 68, 2748-2751.

Inbar, M., and Sachs, L. (1969). Interaction of the carbohydratebinding protein Concanavalin $\mathbf{A}$ with normal and transformed cells. Proc. nat. Acad. Sci. (Wash.), 63, 1418-1425.

Knopf, P. M., Destree, A., and Hyman, R. (1973). Antibody-induced changes in expression of an immunoglobulin surface antigen. J. exp. Med., in press.

Loor, F., Forni, L., and Pernis, B. (1972). The dynamic state of the lymphocyte membrane. Factors affecting the distribution and turnover of surface immunoglobulins. Europ. J. Immunol., 3, 203-212.

Neauport-Sautes, C., Lilly, F., Silvestre, D., and Kourilsky, F. M. (1973). Independence of H-2K and H-2D antigenic determinants on the surface of mouse lymphocytes. J. exp. Med., 137, 511-526.

Nicolson, G. L. (1971). Difference in topology of normal and tumour cell membranes shown by different surface distributions of ferritin-conjugated Concanavalin A. Nature [new Biol.], 233, 244-246.

Nicolson, G. L. (1972). Topography of membrane Concanavalin A sites modified by proteolysis. Nature [new Biol.], 239, 193-197.

Old, L. J., Stockert, E., Boyse, E. A., and Kim, J. H. (1968). Loss of TL antigen from cells exposed to TL antibody: study of the phenomenon in vitro. J. exp. Med., 127, 523-539.

Raff, M. C., and de Petris, S. (1973). Movement of lymphocyte surface antigens and receptors: the fluid nature of the lymphocyte plasma membrane and its immunological significance. Fed. Proc., 32, 48-54.

Sela, B. A., Lis, H., Sharon, N., and Sachs, L. (1971). Quantitation of $\mathrm{N}$-acetyl-D-galactosamine-like sites on the surface membrane of normal and transformed mammalian cells. Biochim. Biophys. Acta (Amst.), 249, 564-568.

Singer, S. J., and Nicolson, G. L. (1972). The fluid mosaic model of the structure of cell membranes. Science, 175, 720-730.

Sjögren, H. O., Hellström, I., Bansal, S. C., and Hellström, K. E (1971). Suggestive evidence that the 'blocking antibodies' of tumor-bearing individuals may be antigen-antibody complexes. Proc. nat. Acad. Sci. (Wash.), 68, 1372-1375.

Stoker, M. G. A. (1964). Regulation of growth and orientation in hamster cells transformed by polyoma virus. Virology, 24, 165-174.

Sundqvist, K. G. (1972). Redistribution of surface antigens-a genera property of animal cells? Nature [new Biol.], 239, 147-149.

Takahashi, T. (1971). Possible examples of antigenic modulation affecting $\mathrm{H}-2$ antigens and cell surface immunoglobulins. Transplant. Proc., 3, 1217-1223.

Taylor, R. B., Duffus, W. P. H., Raff, M. C., and de Petris, S. (1971) Redistribution and pinocytosis of lymphocyte surface immunoglobulin molecules induced by anti-immunoglobulin antibody. Nature [new Biol.], 233, 225-229.

Vitetta, E. S., and Uhr, J. R. (1972). Release of cell surface immunoglobulin by mouse splenic lymphocytes. J. Immunol., 108, 577 579.

Vogt, M., and Dulbecco, R. (1960). Virus-cell interaction with a tumorproducing virus. Proc. nat. Acad. Sci. (Wash.), 46, 365-370.

Warren, L., and Glick, H. C. (1968). Membranes of animal cells. II. The metabolism and turnover of the surface membrane. J. Cell Biol., 37, 729-746.

Weston, J. A., and Hendricks, K. L. (1972). Reversible transformation by urea of contact-inhibited fibroblasts. Proc. nat. Acad. Sci. (Wash.), 69, 3727-3731. 